\title{
A Low Speed Control Algorithm Based on Fuzzy-PI
}

\author{
Ying $\mathrm{Ma}^{1}$, Bin Yan ${ }^{2}$, Sheng $\mathrm{Lu}^{1}$, Congying Deng ${ }^{1}$, Xiang Chen ${ }^{1}$ and Yang Zhao ${ }^{1, *}$ \\ ${ }^{1}$ Institute of virtual design and simulation technology, Chongqing University of Posts and Telecommunications, Chongqing \\ 400065, China. \\ ${ }^{2}$ Huawei Technologies Co Ltd, Chengdu 610041, China. \\ ${ }^{*}$ Corresponding author
}

\begin{abstract}
In order to implement high control performance at low speed $(2 \sim 5 \mathrm{Km} / \mathrm{h})$ for automatic parking system, a speed control algorithm is proposed based on Fuzzy-PI in this paper. First, the desired speed curve is programmed by taking advantage of Laplace-Gaussian curve. In order to avoid fuzzy blind areas, the fuzzy factors of speed error and change rate are adjusted in real-time. Thus, the accuracy of the domain is improved. Then, the desired brake pressure of Electronic Vacuum Booster (EVB) is calculated based on adaptive fuzzy and incremental algorithms. Evaluation on simulation and vehicle test demonstrates that the system based on the improved Fuzzy-PI algorithm can track the desired speed steadily and quickly. The speed and acceleration error during the control process are $\mathbf{- 0 . 5}$ $0.5 \mathrm{Km} / \mathrm{h}$ and $-1 \sim 0.5 \mathrm{~m} / \mathrm{s}^{2}$ respectively.
\end{abstract}

Keywords-autimatic parking; low speed control; LaplaceGauss curve; speed curve program; Electronic Booster

\section{INTRODUCTION}

Automatic parking system is an intelligent assistant system for parking vehicles quickly and safely. The system employs relevant information around the target space, which are acquired by ultrasonic and image sensors to generate reasonable trajectory the position between target vehicle and target space, and control the wheel to steer with computable angle and the driving speed in a low level to finish parking. The vehicle's speed control is one of the key technologies of automatic parking system. The speed is independently controlled is the only standard on distinguishing the automatic or semi-automatic parking system [1] [2]. The parking speed is limited in $2 \sim 5 \mathrm{Km} / \mathrm{h}$ for the safety and comfort [3] [4]. The low speed control can be simplified into the vehicle's longitudinal control since the speed control range is smaller and lateral migration rate may be neglected in the process of parking [5].

The difficulties of the low speed control are higher requirements on control range, steady-state error, response time and vehicle's acceleration. In addition, the nonlinear of the vehicle can also cause great influence on it [6] [7]. A longitudinal fuzzy controller was proposed by Cabello [8], who designed fuzzy rules for controlling throttle and brake. The desired speed was rapidly tracked based on step response. However, the overshoot was larger, for the fuzzy domain saturated zone in the initial stages. A nonlinear brake control algorithm was proposed by Kyongsu et al [9]. It was typically applied to the collision warning/collision avoidance (CW/CA) system. The speed was controlled by operating solenoid valve to control the hydraulic brake. The acceleration curve was programmed to avoid sharply deceleration, and thus the driver's comfort improved. A PID controller was applied to control throttle by Hedrick J K et al [10] [11]. The vehicle's nonlinearity and environment disturbance were often neglected, so the system will be unstable. A longitudinal speed phase control system was proposed by Guan Xin [12]. The throttle was controlled by the acceleration control phase and steady control phase based on resistance integral saturation PID. The control performance was better when the system inputs were sine or steep. However, the adjusting time was increased for avoiding overshoot when the system input is step. A parametric adaptive speed control algorithm was proposed based on a simplified nonlinear vehicle model by Gao Feng [13]. The transmission system stability was also proved by Lyapunov's theory. However, the algorithm cannot be suitable for advanced speed control system, for the complicated calculation.

In summary, traditional low speed control algorithms have still some shortcomings, for example, larger overshoot, long adjustment time and instability. In this paper, a low speed control system is proposed based on Fuzzy-PI algorithm. It integrates the advantages of fuzzy algorithm that independent on the accurate mathematical model and the incremental PI algorithm can quickly and accurately response to the inputs. In addition, the vehicle nonlinearity and the driver's comfort are also considered.

\section{LOW SPEED CONTROL SYSTEM FramewORK}

The speed control system is combined with CW/CA system for the vehicle's safety. Considering the parking spaces is smaller, the target (desired) speed is limited to $(0-5 \mathrm{Km} / \mathrm{h})$, which is less than the vehicle's idle speed range $(5-6 \mathrm{Km} / \mathrm{h})$. In this paper, the vehicle's speed is controlled by the brake power of EVB, the frame structure of low speed control system is illustrated in Figure I. It contains a host computer, lower computer and controller area network (CAN) bus. The lower computer includes wheel speed sensor and EVB. The wheel speed sensor collects vehicle's state dates and transfer to CAN bus. The desired pressure is calculated by a microcontroller unit (MCU) and transferred to EVB by CAN bus. The host computer (MCU) calculates date and transfers control commend.

\section{VEHICLE’S LONGITUDINAL DYNAMICS MODEL}

Considering the tire sliding rate is always neglected in the low speed area, a simplified vehicle's longitudinal dynamics model is introduced to analysis the control algorithm. As 
shown in Figure II, the model includes engine model, torque convert model, automatic transmissions model and vehicle longitudinal dynamic model.

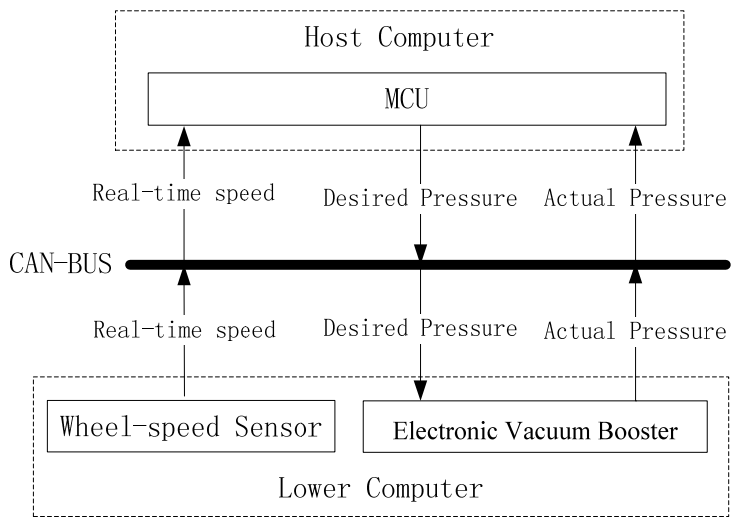

FIGURE I. THE FRAME STRUCTURE OF LOW SPEED CONTROL SYSTEM

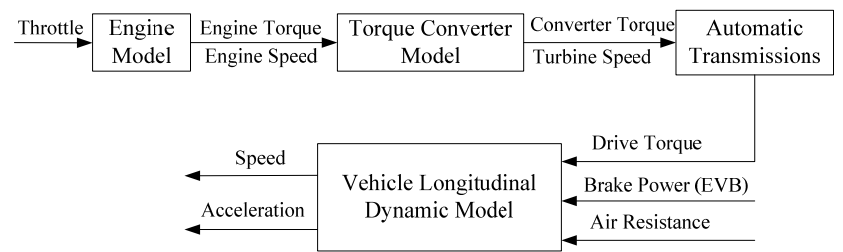

FIGURE II. THE FRAME STRUCTURE OF LOW SPEED CONTROL SYSTEM

In this paper, a $\mathrm{K}$ type driven by front wheel is applied and the road is smooth cement floor. The vehicle's longitudinal dynamics model [14] is defined as

$$
\left\{\begin{array}{l}
m \frac{d v}{d t}=F_{t}-F_{b}-\sum F(v) \\
\sum F(v)=\frac{1}{2} C_{D} A \rho v^{2}+m g f
\end{array}\right.
$$

where $m$ refers to the vehicle's quality; $v$ refers to the vehicle's speed; $F_{t}$ refers to the front wheel traction; $\sum F(v)$ refers to the wheel rolling resistance and air resistance; $C_{D}$ refers to air resistance coefficient; $A$ refers to vehicle's windward area; $\rho$ refers to air density; $g$ refers to gravity acceleration and $f$ refers to rolling resistance coefficient.

The actuator of the low speed control system is EVB. The friction torque $T_{b}$ can be formulated as

$$
\left\{\begin{array}{l}
F_{b}=\frac{T_{b}}{r_{d}} \\
T_{b}=2 R f P
\end{array}\right.
$$

where $r_{d}$ and $f^{\prime}$ refer to tire radius and friction factor; $R$ represents disc braking radius; $P$ represents the force that brake wheel cylinder applied to the brake block; In addition, the relationship between $P$ and the desired pressure $P_{m}$ is expressed as

$$
P=\frac{\pi}{4} P_{m} d^{2}
$$

where $d$ represents wheel cylinder diameter. According to the formula (2) and (3), the relationship between $P_{m}$ and $T_{b}$ is expressed as

$$
T_{b}=\frac{\pi}{2} f P_{m} d^{2} R
$$

Some key simulation parameters are shown in Table I.

TABLE I. KEY SIMULATION PARAMETERS

\begin{tabular}{|c|c|c|c|}
\hline Parameters & Value & Parameters & Value \\
\hline$m$ & $1350 \mathrm{Kg}$ & $\rho$ & $1.29 \mathrm{Kg} / \mathrm{m}^{3}$ \\
\hline$C_{\mathrm{D}}$ & $0.38 \mathrm{~kg} / \mathrm{m}^{3}$ & $R$ & $0.097 \mathrm{~m}$ \\
\hline$A$ & $1.93 \mathrm{~m}^{2}$ & $f$ & 0.02 \\
\hline$r_{\mathrm{d}}$ & $0.28 \mathrm{~m}$ & $d$ & $0.04 \mathrm{~m}$ \\
\hline
\end{tabular}

\section{The SpeEd CONTrol Algorithm}

\section{A. Programming the Speed Curve}

The dynamic performance of the low speed control system is often evaluated on step input [8][10][11][12]. The step response can accurately track the target speed. However, according to the greater speed error at the initial moment, the output saturation is easy to be formed and the acceleration can be changed dramatically. Some researches on the relationship between vehicle's acceleration and driver's comfort shown that the drivers are comfortable when the acceleration is limited in $2-2.5 \mathrm{~m} / \mathrm{s}^{2}$ [9][13][14][15]. In this paper, the problem is effectively solved by programming speed curve. The method on programming speed curve is formulated as

$$
v(n)=\left\{\begin{array}{l}
v(0)+\sum_{0}^{n-n_{0}} \Delta v(n), 0 \leq n_{0} \leq N_{A} \\
v_{\text {tar }} \quad, N_{A}<n_{0}
\end{array}\right.
$$


Where $v(n)$ and $v(0)$ refer to the target speed and initial speed; $\Delta v(n)$ refers to the rate of speed in $n ; N_{A}$ refer to the critical point of the speed programming curve, which is formulated as

$$
N_{A}=\frac{v_{t a r}-v(0)}{3.6 T_{0} a_{t a r}}
$$

where $T_{0}$ refers to the sampling time; $a_{\text {tar }}$ refers to the average acceleration.

As shown in formula (5), the target speed is constant when $n_{0}$ larger than $N_{A}$, so the target speed is tracked by a step function. However, the target speed is increasing when $n_{0}$ smaller than $N_{A}$. In this paper, in order to satisfy driver's comfort and improve the control performance of the speed control system, a Laplace-Gauss curve is applied for programming the increasing speed curve, which is formulated as

$$
\Delta v\left(n_{0}\right)=\left\{\begin{array}{cc}
0 & , n_{0}<0 \\
{\left[v_{\text {tar }}-v(0)\right] \frac{1}{\sqrt{2 \pi} \sigma} e^{-\frac{\left(n_{0}-\mu\right)^{2}}{2 \sigma}}} & , 0 \leq n_{0} \leq N_{A} \\
0 & , N_{A}<n_{0}
\end{array}\right.
$$

where $u$ refers to the central point of $v(n), u=N_{A} / 2 ; \sigma$ refers to the rate of deviation of the speed curve and $u$. According to the Laplace-Gauss curve, we conclude that the speed curve is gathered on the nearby of $u$ when $\sigma$ is smaller, which can lead to the discontinuous target speed. The acceleration can be increased quickly when $\Delta v(n)$ is infinite, which is bad to driver's comfort. Therefore, $\sigma$ is confined from $\mu / 2.4$ to $\mu / 2.6$.

The curves of $v(n)$ and $v_{\text {tar }}$ are illustrated as Figure III and Figure IV. where $v_{\text {real }}=0 \mathrm{Km} / \mathrm{h}, v_{\text {tar }}=3.5 \mathrm{Km} / \mathrm{h}$, $T_{0}=0.01 \mathrm{~s}, \sigma=u / 2.6, a_{\mathrm{tar}}=1 \mathrm{~m} / \mathrm{s}^{2}$.

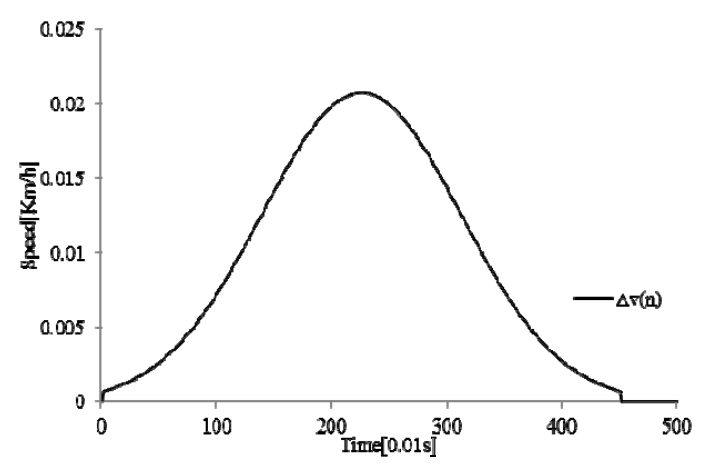

FIGURE III. THE CURVE OF $\Delta v(n)$

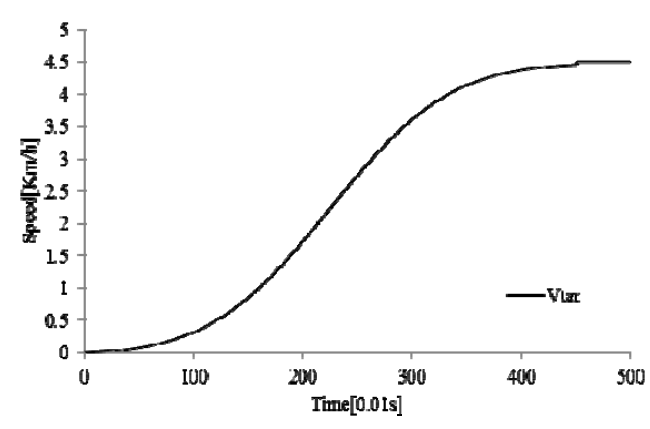

FIGURE IV. THE CURVE OF $v_{\text {tar }}$

\section{B. Improved Fuzzy-PI Algorithm}

In this section, we present an improved Fuzzy-PI algorithm by modifying quantization factor. According to the abilities of the speed controller, it is more reasonable to design the fuzzy rules less than nine. In this paper, the membership function is divided into five parts, which is expressed as

$$
N=\{-2 / N B,-1 / N S, 0 / Z R, 1 / P S, 2 / P B\}
$$

In the traditional fuzzy algorithm, both the quantization factor and the mapping value from the actual domain to the fuzzy domain are constant. At the initial time, the speed error and its integration is extreme larger when the system input is step signal. It can lead to the fuzzy domain is always stay in saturated areas (NB) and the output is also constant. In addition, the acceleration is also larger in low speed area and the fuzzy membership is often jumped in the nearby of the desired speed. The output increase quickly and the speed decreased sharply. However, the blind area of fuzzy domain is still be introduced, for the deviation of speed error and its integration are smaller.

The precision of the low speed control system is improved by modifying quantization factor dynamically. Therefore, the problem of blind areas and saturation areas are solved effectively. The relationship between quantization factors $(\operatorname{Ke}(n), \operatorname{Kec}(n))$ and the desired speed $(v(n))$ is expressed as 


$$
K_{a}(n)=\frac{2}{k_{a} v(n)}
$$

where $k_{a}$ refers to the scale factor, $a \in\{e(n), e c(n)\}$.

In the following, we design the fuzzy rules and membership function. The fuzzy value $\left(n_{a}\right)$ of deviation $e(n)$ $\left(e(n)=v_{\text {real }}(n)-v(n)\right)$ and its rate $e c(n)$ are obtained by the maximum membership degree method. The relationship can be expressed as

$$
n_{a}=\left\{\begin{array}{l}
2, a \cdot K_{a} \geq 2 \\
\operatorname{sgn}\left(a \cdot K_{a}\right) \operatorname{int}\left(\left|a \cdot K_{a}\right|+0.5\right), a \cdot K_{a}<2 \\
-2, a \cdot K_{a} \leq-2
\end{array}\right.
$$

According to the theoretical analysis and driver's operation experience, we can obtain the fuzzy rules, which are shown in Table II and Table III.

TABLE II. THE FUZZY RULES OF $K_{P}$

\begin{tabular}{|c|c|c|c|}
\hline \multirow{2}{*}{$|\mathbf{e c}(\mathbf{n})|$} & \multicolumn{3}{|c|}{$\mid \mathbf{e ( n ) |}$} \\
\cline { 2 - 4 } & $\mathrm{B}$ & $\mathrm{S}$ & $\mathrm{ZR}$ \\
\hline $\mathrm{B}$ & $\mathrm{S}$ & $\mathrm{S}$ & $\mathrm{S}$ \\
\hline $\mathrm{S}$ & $\mathrm{B}$ & $\mathrm{B}$ & $\mathrm{B}$ \\
\hline ZR & $\mathrm{B}$ & $\mathrm{B}$ & $\mathrm{ZR}$ \\
\hline
\end{tabular}

TABLE III. THE FUZZY RULES OF $K_{I}$

\begin{tabular}{|c|c|c|c|}
\hline \multirow{2}{*}{$|\mathbf{e c}(\mathbf{n})|$} & \multicolumn{3}{|c|}{$\mid \mathbf{e ( n ) |}$} \\
\cline { 2 - 4 } & $\mathrm{B}$ & $\mathrm{S}$ & $\mathrm{ZR}$ \\
\hline $\mathrm{B}$ & $\mathrm{ZR}$ & $\mathrm{S}$ & $\mathrm{B}$ \\
\hline $\mathrm{S}$ & $\mathrm{ZR}$ & $\mathrm{B}$ & $\mathrm{B}$ \\
\hline $\mathrm{ZR}$ & $\mathrm{ZR}$ & $\mathrm{B}$ & $\mathrm{ZR}$ \\
\hline
\end{tabular}

(1) In order to decrease the response time, system time constant and damping coefficient, $K_{P}$ can be larger if $|e(n)|$ is also larger. In addition, $K_{I}=0$ avoid excessive overshoot.

(2) In order to decrease the response time and damping coefficient, $K_{P}$ can be smaller if $|e(n)|$ is medium. In addition, $K_{I}$ can be increased appropriately.

(3) In order to increase the stability of the system and avoid the shock in the equilibrium, $K_{P}$ and $K_{I}$ can be larger if $|e(n)|$ is smaller. The mapping relationship between the fuzzy value and actual value is also presented as follows.

$$
\left\{\begin{array}{l}
K_{P}(n)=\{3 / N B, 1 / N S, 2 / Z R, 5 / P S, 10 / P B\} \\
K_{I}(n)=\{3 / N B, 2 / N S, 1 / Z R, 3 / P S, 5 / P B\}
\end{array}\right.
$$

\section{Designing Fuzzy-PI Controller}

The controller structure based on the improved Fuzzy-PI and its flowchart are expressed as Figure V and Figure VI.

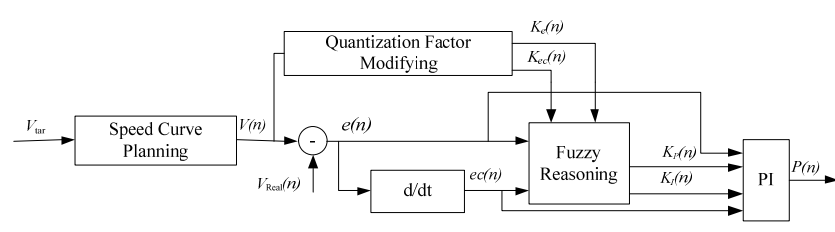

FIGURE V. THE CONTROLLER STRUCTURE BASED ON THE IMPROVED FUZZY-PI

As shown in Figure VI, the controller flowchart is divided into three layers, including top controller, middle controller and lower controller. In the top controller, the Laplace-Gauss curve is applied for programming $\Delta v(n)$ until the desired speed is equal to the target speed $v_{\text {tar }}$ and the quantification factor $\left(K_{e}(n), K_{e c}(n)\right)$ is modified on line. In the middle controller, $e(n)$ and $e c(n)$ are calculated, $K_{p}(n)$ and $K_{I}(n)$ are also determined by inquiring fuzzy rules (Table II, Table III). The desired pressure is obtained based on incremental PI algorithm by the lower controller. Finally, the vehicle's speed is controlled by the output the braking power of EVB.

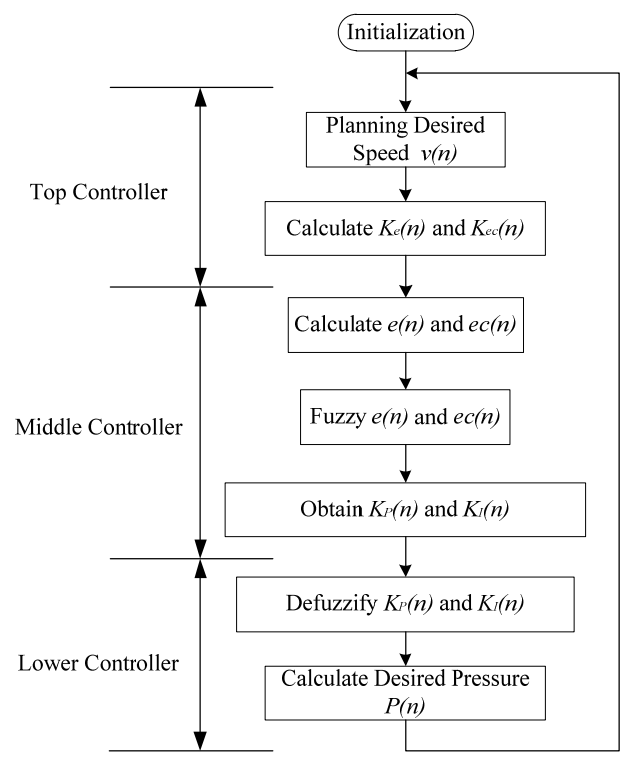

FIGURE VI. THE CONTROLLER FLOWCHART

\section{RESUltS AND DiscUSSIONS}

An automatic gear vehicle is used in the experiment. Meanwhile, a mathematical model of the vehicle motion is also established based on vehicle's parameters and formula (1)-(5), which is shown as follows 


$$
1350 v(k)=65627-0.47 v(k)^{2}-867.13 P(k)
$$

where $P(k)$ refers to the desire pressure. The test car is back running in the dry cement ground. The speed comparison curve of actual and simulation based on formula (12) are illustrated in Figure VII when the pressure is zero.

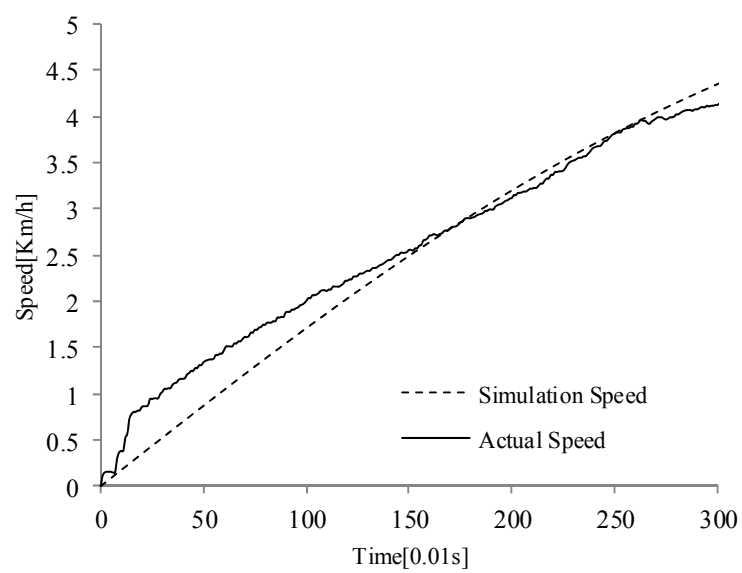

FIGURE VII. THE SPEED COMPARISON CURVE WITHOUT PRESURE

As shown in Figure VII, the simulation speed is appropriately equal to the actual speed when the actual speed is more than $1 \mathrm{Km} / \mathrm{h}$. However, the speed error between simulation and actual is still larger when the actual speed is less than $1 \mathrm{Km} / \mathrm{h}$. The reason is appearing the measuring blind area in the condition. In the experiment, the speed control range is $2 \sim 5 \mathrm{Km} / \mathrm{h}$, so the influence can be neglected. In order to compare the performance between the improved Fuzzy-PI algorithm and traditional Fuzzy-PI algorithm, a simulation and actual experiment are implemented respectively. The condition of actual experiment is further divided into linear and steering. The steering wheel is fixed in the condition of steering. In addition, the driver can manually set the desired speed and the desired speed is defined as $2.5 \mathrm{Km} / \mathrm{h}, 3.5 \mathrm{Km} / \mathrm{h}$ and $4.5 \mathrm{Km} / \mathrm{h}$ respectively. The sampling time and control period time are 10 $\mathrm{ms}$ and $50 \mathrm{~ms}$. The simulation and actual experiment results are illustrated as Figure VIII $\sim$ Figure XIII.

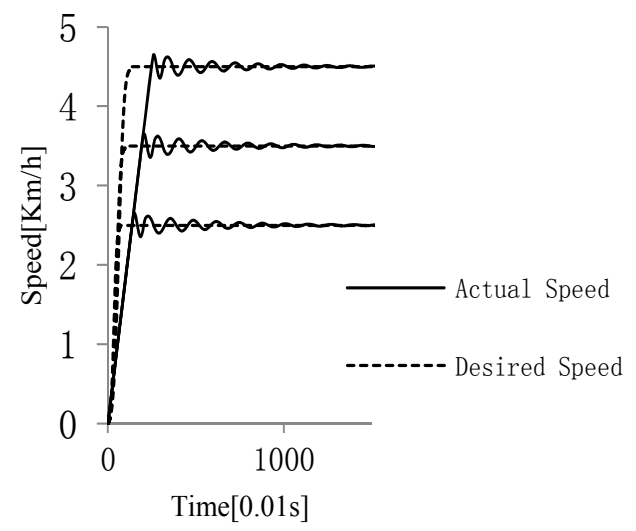

FIGURE VIII. THE SIMULATION RESULTS OF TRADITIONAL FUZZY-PI

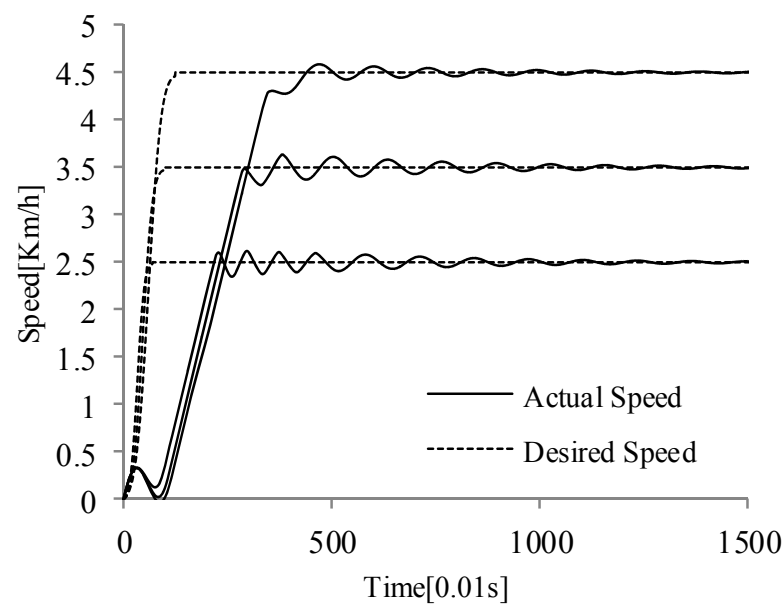

FIGURE IX. THE SIMULATION RESULTS OF IMPROVED FUZZY-PI

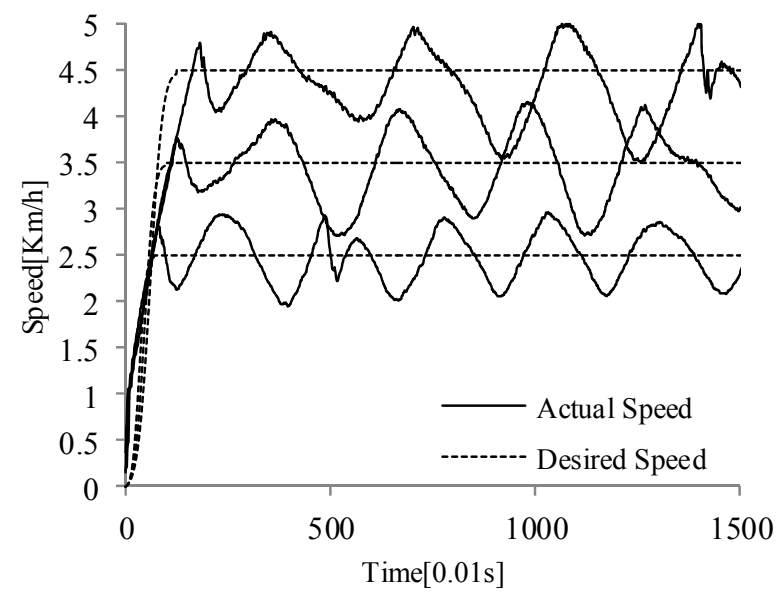

FIGURE X. THE LINEAR EXPERIMENT OF TRADITIONAL FUZZY-PI

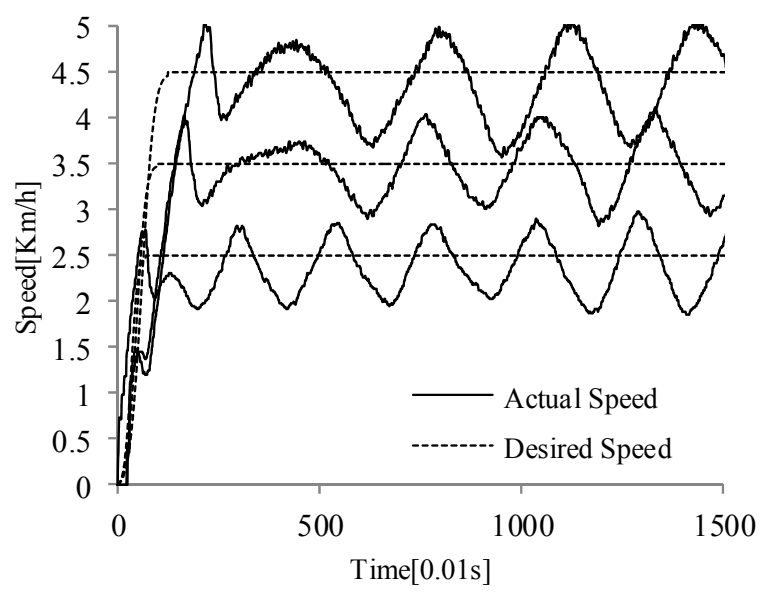

FIGURE XI. THE LINEAR EXPERIMENT OF INPROVED FUZZY-PI 


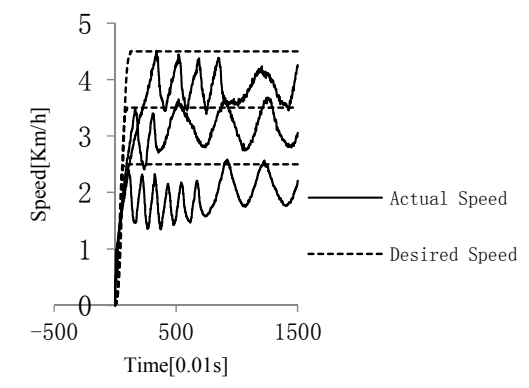

FIGURE XII. THE STEERING EXPERIMENT OF TRADITIONAL FUZZY-PI

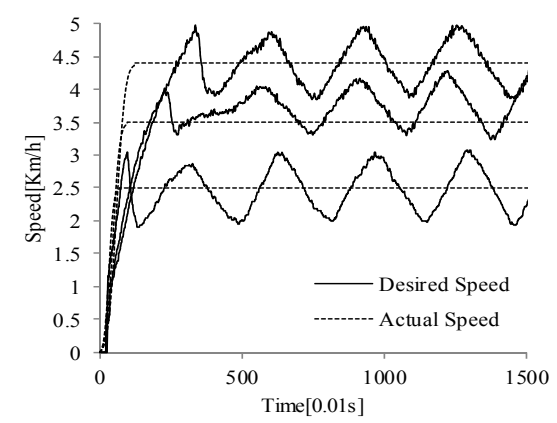

As shown in Figure VIII Figure XIII, both the traditional Fuzzy-PI and improved Fuzzy-PI can control vehicle's speed. The static error is appropriately zero in the simulation. However, in the actual experiment, speed vehicle's speed is fluctuant in the near of the desired speed, which the influence on the structure characteristics of EVB. The output of EVB is unstable requiring the low controller to switch magnetic value. The comparison between simulation and experiment are illustrated as Table IV. The peak time is just the same in both simulation and experiment. According to the static error and overshoot, the improved Fuzzy-PI is better than traditional Fuzzy-PI. For the improved Fuzzy-PI algorithm, the peak time is still smaller, and the static error and overshoot is also decreased respectively.

In various desired speed, the acceleration respond curves are illustrated in Figure XIV Figure XVI.

FIGURE XIII. THE STEERING EXPERIMENT OF IMPROVED FUZZY-

TABLE IV. THE COMPARISON OF CONTROL PERFORMANCE

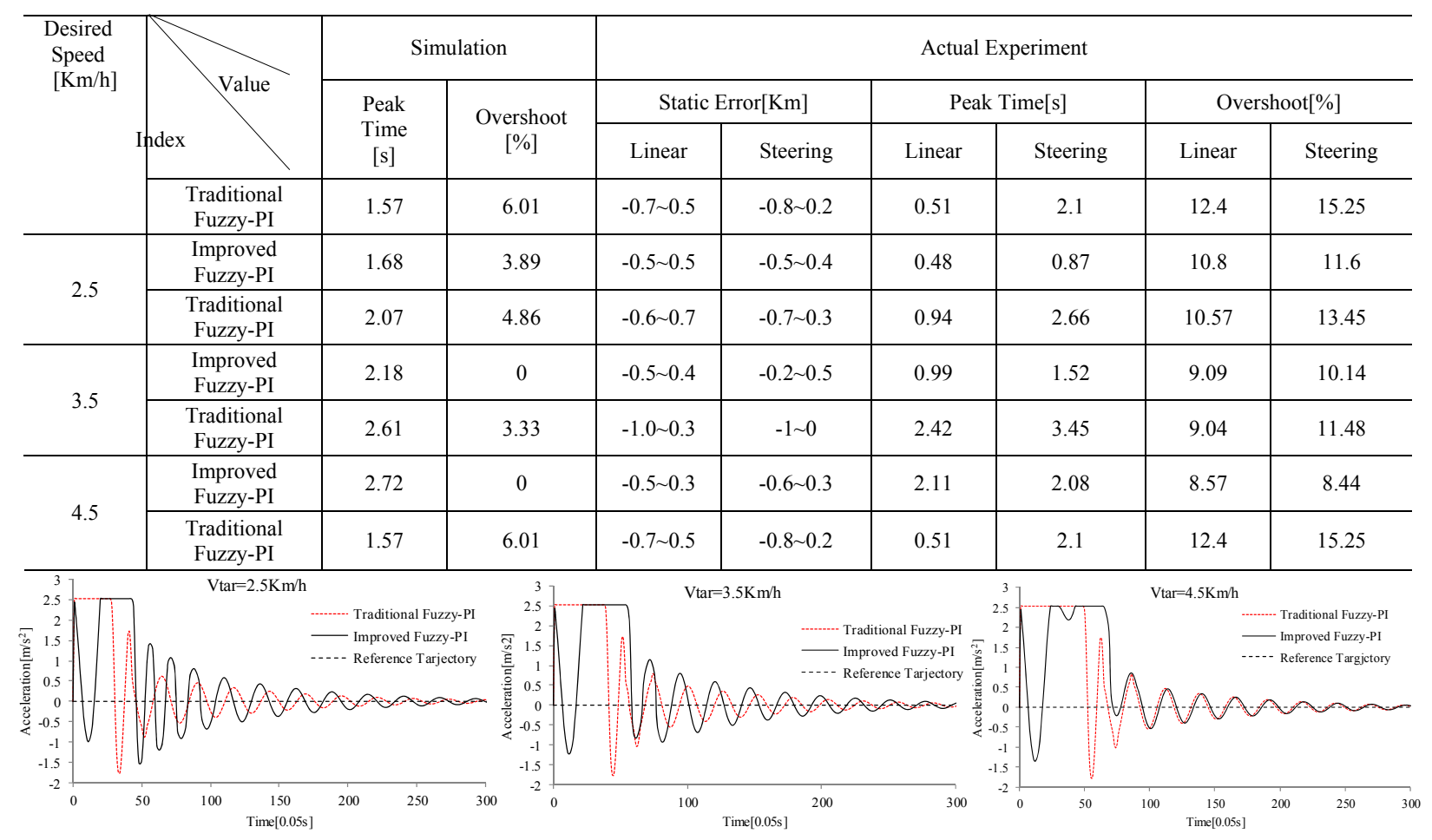

FIGURE XIV. THE SIMULATION RESULT IN DIFFERENT DESIRED SPEED 

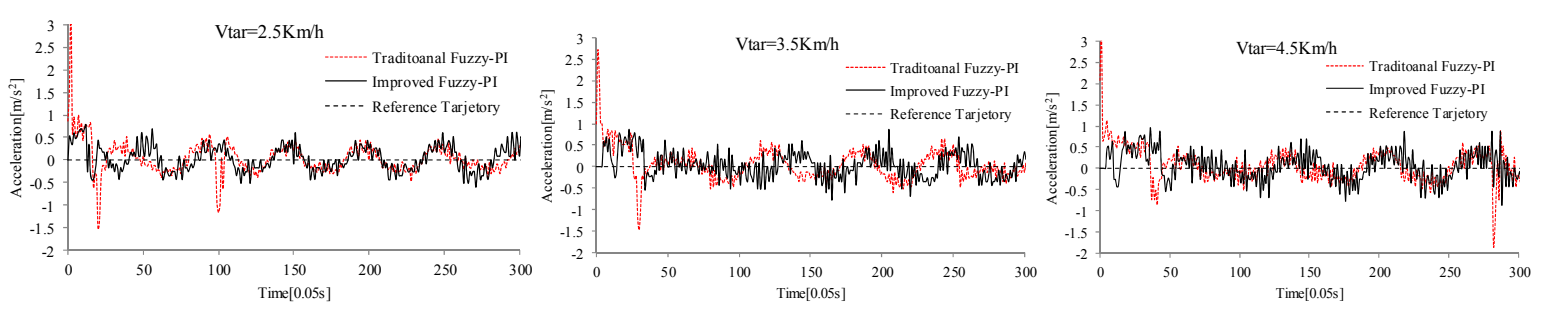

FIGURE XV. THE LINEAR EXPERIMENT IN DIFFERENT DESIRED SPEED
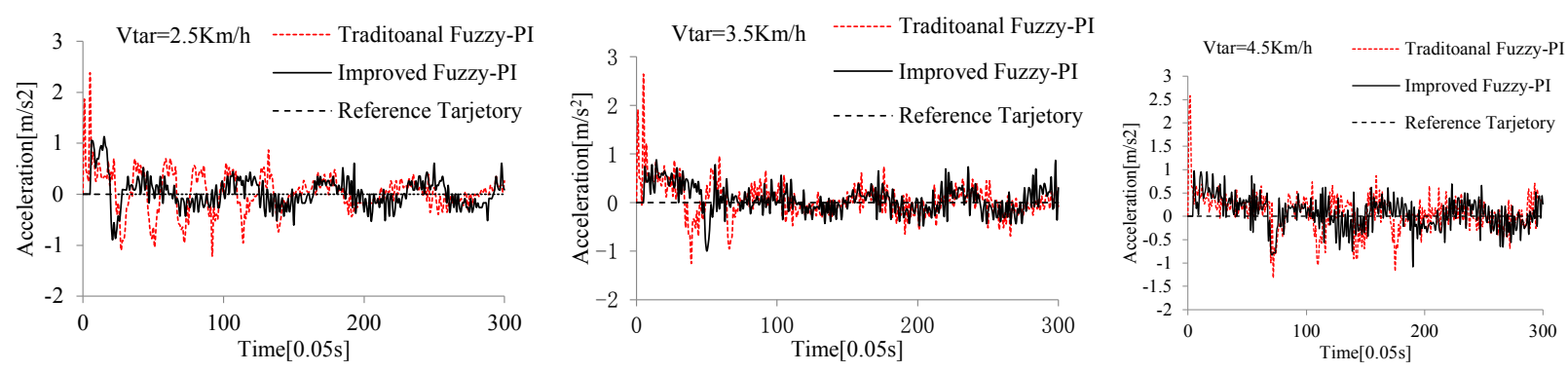

FIGURE XVI. THE STEERING EXPERIMENT IN DIFFERENT DESIRED SPEED

As shown in Figure XIV, the acceleration of traditional Fuzzy-PI and improved Fuzzy-PI are fluctuation in the range of $-1.3 \sim 1.3 \mathrm{~m} / \mathrm{s}^{2}$ and $-2 \sim 2 \mathrm{~m} / \mathrm{s}^{2}$ respectively. As shown in Figure $\mathrm{XV}$ and Figure XVI, the acceleration of traditional Fuzzy-PI is varying in the range of $-2 \sim 2.5 \mathrm{~m} / \mathrm{s}^{2}$. In addition, many peaks are found in the process. However, the acceleration of improved Fuzzy-PI is varying in the range of $-1 \sim 0.5 \mathrm{~m} / \mathrm{s}^{2}$ and does not produce peak in the whole process. Above all, we can conclude that the acceleration of the improved Fuzzy-PI algorithm is more small and smooth than the traditional Fuzzy-PI. The actual experiment process of automatic parking is illustrated as Figure XVII.

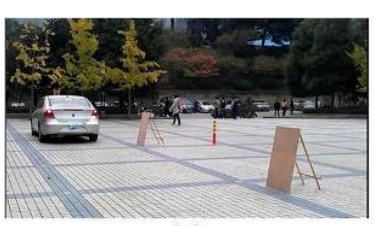

(a)

(c)

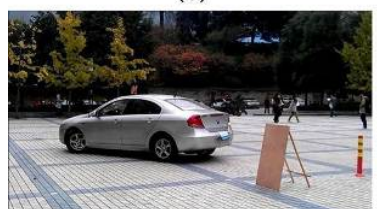

(e)

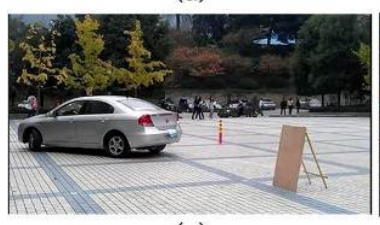

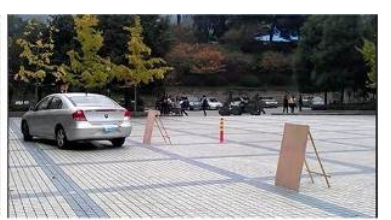

(b)

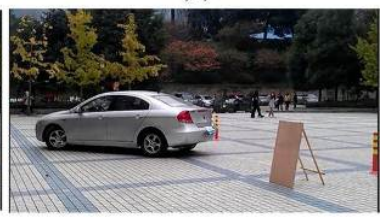

(d)

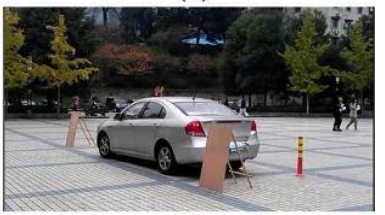

(f)
FIGURE XVII. THE REAL VEHICLE EXPERIMENT OF FULLAUTOMATIC PARKING SYSTEM

\section{CONCLUSIONS}

(1) A speed control algorithm is proposed based on FuzzyPI. The desired speed curve is programmed by taking advantage of Laplace-Gaussian curve. In addition, the fuzzy factors of speed error and change rate are adjusted in real-time. Then, the desired pressure is calculated by means of adaptive fuzzy and incremental algorithms.

(2) Evaluation on simulation and vehicle test demonstrates that the system based on the improved Fuzzy-PI algorithm can track the desired speed steadily and quickly. The speed and acceleration error during the control process are $-0.5 \sim 0.5 \mathrm{Km} / \mathrm{h}$ and $-1 \sim 0.5 \mathrm{~m} / \mathrm{s}^{2}$ respectively.

\section{ACKNOWLEDGMENT}

This work is supported by Chongqing Research Program of Basic Research and Frontier Technology (cstc2016jcyjA0443, cstc2016jcyjA0574), China Postdoctoral Science Foundation funded project (2018M633314) and Chongqing Education Commission (KJ1600423, KJ1600422, KJ1600466).

\section{REFERENCES}

[1] H.G. Jung, D.S. Kim and J. Kim, "Light-Stripe-Projection-Based Target Position Designation for Intelligent Parking-Assist System", IEEE Intelligent Transportation Systems, vol. 11, 2010, pp.942-953.

[2] J.K. Suhr and H.G. Jung, "Full-automatic recognition of various parking slot markings using a hierarchical tree structure", Optical Engineering, vol. 52, no. 3, 2013, pp.1-14.

[3] F.C. Wang, "Research of automatic parallel parking system", Hefei: University of Science and Technology of China, 2010.

[4] K. Wu, "Research of the intelligent automatic parking system", Nanjing: Nanjing University of Science and Technology, 2008.

[5] D.Z. Hou, "Development of vehicle longitudinal collision avoidance system”, Beijing: Tsinghua University, 2004.

[6] J.K. Park, B.S. Kim, D.E. Seo and D.S. Kim, "Parking space detection using ultrasonic sensor in parking assistance system", IEEE Intelligent Vehicles Symposium, 2008, pp.1039-1044. 
[7] S. Lu, M. Lian, M. Liu, C. cho, and C. Piao, "Adaptive fuzzy sliding mode control for electric power steering system", Journal of Machanical Science \& Technology, vol. 6, no. 31, 2017, 2643-2650.

[8] F. Cabello, A. Acuna and P. Vallejos, "Design and validation of a fuzzy longitudinal controller based on a vehicle dynamic simulator", IEEE International Conference on Control and Automation, 2011, pp.9971002 .

[9] K. Yi and J. Chung, "Nonlinear Brake Control for Vehicle CW/CA System", ASME/IEEE Transactions on Mechatronic, vol. 6, no. 1, 2001, pp. $17-25$.

[10] J.K. Hedrick, "Control Issues in Automated Highway Systems", IEEE Control Systems, 1994, pp.21-32.

[11] J.C. Gerdes and J.K. Hedrick, "Vehicle Speed and Spacing Control via Coordinated Throttle and Brake Actuation", Control Engineering Practice, vol. 5, no. 11, 1997, pp.1607-1614.

[12] X. Guan, W.F. Cui and X. Jia, "Vehicle longitudinal speed split-phase control", Journal of Jilin University, vol. 2, no. 43, 2013, pp.273-277.

[13] F. Gao, J.Q. Wang, D.Z. Hou and K.Q. Li, "Electronically assisted braking system for vehicles based on a high-speed on/off value", Journal of Tsinghua University, vol. 44, no. 11, 2004, pp.1532-1535.

[14] N.N. Yang, H.W. Liang and S.P. Wang, "Trajectory programming method and simulation research of parallel parking", Electronic Measurement Technology, vol. 34, no. 1, 2011, pp.42-45.

[15] J.J. Xia and C.L. Li, "Vehicle control of CVT automotive based on engine brake", MACHINE TOOL \& HYDRAULICS, vol. 39 , no. 17, 2011, pp.33-36. 